\title{
Twenty four hour care in inner cities: two years' out of hours workload in east London general practice
}

\author{
Anna Eleri Livingstone, John Anthony Jewell, John Robson
}

\begin{abstract}
Two inner city general practices in east London jointly provide care outside normal working hours without using deputising services for about 14000 patients. The statistics on workload were reviewed for 1987 and 1988. An overall rate of face to face consultations of 4.1 per patient per year was recorded, there being 115965 consultations over two years for a mean list size of 14174 patients. Four per cent (4737) of such consultations were outside normal working hours. The annual rate of visiting outside normal hours was $128 \cdot 1$ per 1000 patients in 1987 (1793 visits) and 131.5 per 1000 in 1988 (1888 visits). The rates of night visiting were 18.8 (262 visits) and 18.9 (271 visits) per 1000 patients in 1987 and 1988 respectively. Only $24 \%$ of all the requests for medical help out of hours $(1483 / 6220)$ were dealt with by advice given on the telephone.

The high rates of consultation outside normal working hours with only a small proportion being dealt with on the telephone alone may be explained by indices of deprivation. Local rotas for out of hours work are a good compromise between meeting the needs of patients and doctors in deprived areas, but there are financial implications for inner cities.
\end{abstract}

\section{Introduction}

There is still a shortage of data on the workload of general practitioners working in deprived areas, although what data there are suggest that it is heavier and more taxing than in prosperous areas. This study not only is part of an ongoing audit by the practices concerned but also documents workload in inner east London as a contribution to the discussion of appropriate patterns of care, staffing, and remuneration in deprived areas.

Despite longstanding government recognition of the health problems of inner cities the "inverse care law" still applies, ' and there has been little effective change in policy. The 1981 Acheson report on primary care in inner London made 115 recommendations. ${ }^{2}$ Few have been acted on. Tower Hamlets lags 15 years behind England and Wales as a whole in the development of general practice when indicators such as growth of group practice, purpose built premises, and employment of ancillary staff are considered. ${ }^{3}$ The contraction of hospital services in the 1970s and 1980s has been pronounced in inner London. ${ }^{4}$ In Tower Hamlets five accident and" emergency departments have closed in the past 15 years despite the strong tradition of patients using such departments for primary care in the district.

We present statistics for the workload outside normal working hours in two closely linked practices in the E14 district of Tower Hamlets over two years. We have not attempted to describe the nature or outcome of calls or to define what is an appropriate call to general practitioners outside normal working hours. Doctors' and patients' views on what constitutes an appropriate out of hours call would differ somewhat, and detailed discussion of illness associated with social class and the non-medical factors leading to calls lie outside the remit of our audit.

\section{Practices and methods}

The patients served by our practices are among the most deprived in England and Wales. The figure shows the high deprivation indices for the wards in our practice according to Townsend and Jarman scores (see appendix). ${ }^{56}$ Housing is poor and mostly owned by the local authority, and rates of telephone and car ownership are low. We have a high proportion of young children and single parent families. It is a multiracial area, with over $40 \%$ of births in the district being to mothers of Bangladeshi origin. Our annual rates of patient turnover are up to a fifth.

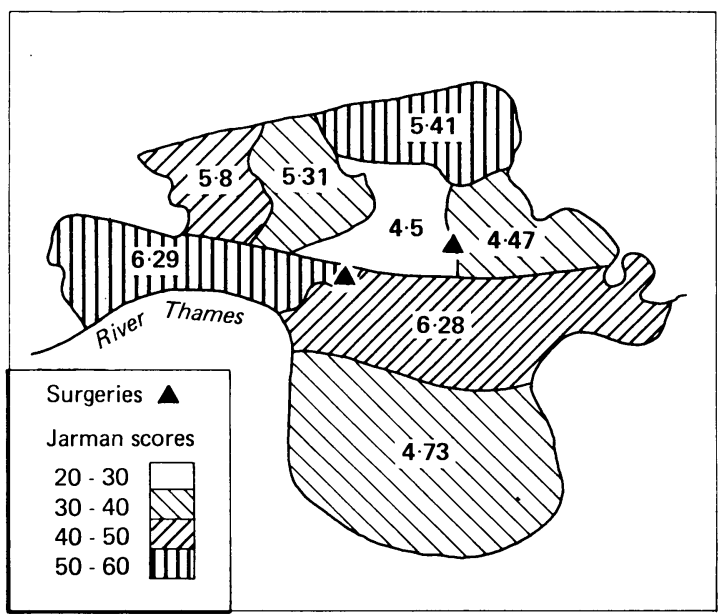

Foint practice area showing Townsend $Z$ scores (numbers on hatching) and farman underprivileged area indices" for each ward based on dat from 1981 census. Townsend $Z$ scores in greater London range from 8.42 to -11.01 (average 0 ) and farman underprivileged area indices in England from $72 \cdot 95$ to $-62 \cdot 52$ (average 0$)$

Both practices grew in the early 'eighties from the merging of several traditional, mainly singlehanded east end practices, which used to delegate calls outside normal working hours (out of hours calls) to deputising services. They are now staffed by eight local vocationally trained principals (four men and four women), and the two health centres are open from 0830 to 1830 from Monday to Friday. All eight principals and the trainees cover out of hours calls on a rota. Out of hours calls are those received at weekends, on bank holidays, and between 1830 and 0830 on weekdays. The patient telephones a commercial medical answering service, which pages or telephones 


\begin{tabular}{|c|c|c|c|c|c|c|c|c|}
\hline & \multicolumn{4}{|c|}{1987} & \multicolumn{4}{|c|}{1988} \\
\hline & \multicolumn{2}{|c|}{ No } & \multicolumn{2}{|c|}{ Rate } & \multicolumn{2}{|c|}{ No } & \multicolumn{2}{|c|}{ Rate } \\
\hline & \multicolumn{8}{|c|}{ All out of hours consultations } \\
\hline Total consultations & & 3137 & & $224 \cdot 1$ & & 3083 & & $214 \cdot 9$ \\
\hline Emergency surgery & 560 & & $40 \cdot 0$ & & 496 & & $34 \cdot 6$ & \\
\hline Visits & 1793 & & $128 \cdot 1$ & & 1888 & & $131 \cdot 5$ & \\
\hline Telephone advice only & 784 & & $56 \cdot 0$ & & 699 & & $48 \cdot 7$ & \\
\hline \multirow[t]{2}{*}{ Total consultations in person } & & 2353 & & $168 \cdot 1$ & & 2384 & & $166 \cdot 1$ \\
\hline & \multicolumn{8}{|c|}{ Consultations from 2300 to 0700} \\
\hline Total consultations & & 445 & & $31 \cdot 8$ & & 453 & & $31 \cdot 8$ \\
\hline Visits & 262 & & $18 \cdot 8$ & & 271 & & $18 \cdot 9$ & \\
\hline \multirow{2}{*}{ Telephone advice only } & 183 & & $13 \cdot 1$ & & 182 & & $12 \cdot 7$ & \\
\hline & \multicolumn{8}{|c|}{ Consultations during normal working hours $†$} \\
\hline Total consultations in person & & 54389 & & $3885 \cdot 5$ & & 56839 & & $3961 \cdot 4$ \\
\hline Attendances & 50445 & & $3603 \cdot 6$ & & 53028 & & $3695 \cdot 8$ & \\
\hline \multirow[t]{2}{*}{ Visits } & 3944 & & $281 \cdot 8$ & & 3811 & & $265 \cdot 6$ & \\
\hline & \multicolumn{8}{|c|}{ Consultations per $24 h \dagger$} \\
\hline Total consultations in person & & 56742 & & $4054 \cdot 6$ & & 59223 & & $4127 \cdot 6$ \\
\hline Attendances & 51005 & & $36+3 \cdot 6$ & & 53524 & & $3730 \cdot 4$ & \\
\hline Visits & 5737 & & $409 \cdot 9$ & & 5699 & & $397 \cdot 2$ & \\
\hline
\end{tabular}

* Mean joint list size according to family practitioner list rose slowly from 13864 to 14483 over period of study. Annual figures are averages of quarterly figures with list sizes at start of quarter taken as denominator.

tExcluding advice given on telephone.
6220 consultations outside normal working hours. Between 2300 and 0700,365 calls entailed giving advice on the telephone alone, which was $41 \%$ of the total 898 consultations at this time. On average sleep was disturbed just over once a night when a doctor was on duty. There were also 1056 attendances at the emergency surgery, which was $17 \%$ of the total number of consultations outside normal working hours.

During the study there were 115965 face to face consultations, 4737 , or $4 \%$, being outside normal working hours. Table I shows the numbers of patients consulting a general practitioner and the consultation rates per 1000 patients in 1987 and 1988 .

\section{Discussion}

The high rates of consultations outside normal working hours that are characteristic of deprived areas are confirmed by our results. Table II shows the high rates of all out of hours consultations and those at night in practices in deprived urban areas, including ours, compared with other urban and rural settings. City and East London Family Practitioner Committee pays FP8 claims at the rate of $15 \cdot 2$ per 1000 patients (18.1 corrected for inflation). Most of these calls are dealt with by deputising services, which cannot usually give advice on the telephone. ${ }^{12}$ The potential workload is greater still as it is well documented that patients attend accident and emergency departments in Tower Hamlets with problems more appropriately managed in general practice. Davison et al found that $86 \%$ of the subjects in their sample attended our local accident and emergency department without having previously consulted their general practitioner. ${ }^{13}$ They also considered $39 \%$ of the conditions to be neither accidents nor emergencies.

In our practices advice was given on the telephone alone in $24 \%$ of all calls ( 1483 out of 6220 ) and in $41 \%$ (365 out of 898) of night calls (from 2300 to 0700). In Cleveland Marsh et al gave advice on the telephone in $60 \%$ of the calls outside normal working hours, which suggests a lower threshold for responding to a call with a home visit in deprived areas. As Riddell said, "The young or lone parents were ill-equipped to cope even with advice." Low rates of telephone ownership and high rates of broken callboxes also decrease the extent to which advice can be given on the telephone. Our consultation rate per 24 hours is high at over four for each patient on the list a year, but crude rates do not adequately describe workload. They do not show the content and duration of the consultations, the difficulties encountered with patients with multiple problems and language problems, the difficulties of access in home visits, or the time spent in meetings, liaison, and administration.

The Acheson report criticised the inaccessibility of many inner London general practitioners and the problems incurred in the heavy use of deputising services. ${ }^{2}$ We have not used deputising services in our practices in an attempt to improve the quality of care. In improving accessibility by day and night we have undoubtedly increased the workload of the practice. As a team we provide continuity of care, with prompt

In the two years of the study a mean population of 14174 received 3681 visits after hours, 533 of which were requested and carried out between 2300 and 0700 (table I). Advice was given on the telephone alone in 1483 consultations, which was $24 \%$ of the total

TABLE II -Variation in call rates reported by practices (per 1000 patients per year) in relation to type of area

\begin{tabular}{|c|c|c|c|c|c|c|c|c|c|c|}
\hline \multirow[b]{2}{*}{ Location } & \multirow[b]{2}{*}{ Type of area } & \multirow[b]{2}{*}{ List size } & \multirow[b]{2}{*}{ Year } & \multicolumn{3}{|c|}{ Out of hours calls (2300 to 0700 ) } & \multicolumn{4}{|c|}{ Out of hours calls (total) } \\
\hline & & & & Telephone & Visit & Total & Telephone & Visit & Surgery & Total \\
\hline Inverclyde & Industrial & 63249 & $1982-4$ & & $35 \cdot 2$ & & Not available & & & \\
\hline Last London & Inner city & 14174 & $1987-8$ & $12 \cdot 9$ & $18 \cdot 8$ & $31 \cdot 8$ & $53 \cdot 4$ & $120 \cdot 3$ & $37 \cdot 3$ & $219 \cdot 5$ \\
\hline Glasgow" & Housing estate and inner city & 19730 & 1977 & & $16 \cdot 8$ & & & $83 \cdot 3$ & & \\
\hline Stockton on Tees" & Suburban & 15669 & $1984-5$ & $9 \cdot 8$ & $13 \cdot 6$ & $23 \cdot 4$ & $76 \cdot 1$ & $47 \cdot 5$ & $6 \cdot 3$ & $129 \cdot 9$ \\
\hline Whitby"' & Coastal town and rural & 15274 & 1974 & & $10 \cdot 6$ & & Not available & & & \\
\hline Kent" & Rural & 12000 & 1979 & $8 \cdot 3$ & $7 \cdot 7$ & $16 \cdot 0$ & & & Not included & 122 \\
\hline
\end{tabular}


handover and consistent policies of management. We are familiar with local hospital and community resources and staff, have access to medical notes, know the area, and are often known to the patients.

Discussion of the provision of out of hours care is a notable omission from the white paper on primary care $^{14}$ and Working for Patients. ${ }^{15}$ These have been followed by the proposed new contract, ${ }^{16}$ which would give lower payments for deputised night visits but does not clarify support for local rotas such as ours.

Out of hours work is stressful as well as at times rewarding. This may contribute to the high use of deputising services by inner city general practitioners. ${ }^{17}$ Fatigue is known to impair judgment, and despite a rota we still have times when we are on duty continuously for 36 hours. ${ }^{18}$ Doctors visiting on their own may worry about increasing violence in inner city areas. ${ }^{19}$ Finally, general practitioners need to live near their practices, which in London often combines deprived surroundings with prohibitively expensive housing. Our practices have not achieved the review body's target net remuneration and confirm the findings of Bosanquet and Leese of a low gross income per partner in inner London..$^{20} \mathrm{~A}$ London weighting allowance for high expenses as well as a deprivation allowance for high workload would help us achieve average income.

Good quality out of hours care in general practice in deprived areas of London has financial implications. If the care is provided by local practices staffing has to be adequate and therefore list sizes have to be small enough to provide time off to recuperate without loss of earnings or placing an intolerable burden on partners. All out of hours work should be better recompensed as the long hours worked are both stressful and poorly paid. With a high patient workload list sizes need to be smaller to cope. Though other alternatives have been proposed, ${ }^{421}$ we believe that well financed local rotas for out of hours work provide the best compromise between meeting the needs of the patients in deprived areas and those of their doctors.

We thank the other doctors working in both practices for their help: Drs Kambiz Boomla, Felicity Challoner, Caroline Lea-Cox, Janet Self, Emma Storr, Jane Taylor, Mairi Todd, David White, and David Widgery. We also thank the reception and management staff at both practices, who have worked hard on collating the information, particularly Vicky Jones, Linda Darby, and Maggie Falshaw.

\section{Appendix}

JARMAN AND TOWNSEND DEPRIVATION SCORES

Over the past decade several scores have been developed that aim at ranking areas in terms of deprivation or workload for health services. The Townsend $\mathrm{Z}$ score aims at being an economic indicator and is a multiple deprivation index giving four variables from the census (unemployment, overcrowding, renting, and not owning a car) equal weight. It specifically excludes variables such as age and ethnic group as not being in themselves directly representative of economic state.

The Jarman underprivileged area index, on the other hand, is an indicator of workload in general practice. ${ }^{6}$ It is a weighted score of eight variables from the census that are not amenable to intervention by the health services - that is, the numbers of elderly people living alone, children under 5 , lone parents, and unskilled and unemployed workers; overcrowding; changing address; and belonging to an ethnic minority group. The eight variables were derived from a national survey of factors that general practitioners considered affected workload from among those mentioned by doctors in London to the Acheson committee. The score was developed as a way of locating areas where extra support might be given to general practice and has in fact been adopted as the basis for the weighted capitation fee in the government's new contract for general practitioners. ${ }^{16}$ It has, however, been criticised for giving low weighting to areas with, for example, high morbidity, mortality, and unemployment, but low proportions of elderly people or people from ethnic minority groups. It is a useful indicator of inner city workload but is not a direct measure of deprivation.

1 Hart J'T. The inverse care law. Lancet 1971;i:405-12.

2 London Health Care Planning Consortium Study Group. Primary health care in inner London. London: London Health Care Planning Consortium, 1981. (Acheson report.)

3 Hull S, Livingstone A, Dunford A The general practitioner in the inner city. J R Coll Gen Pract 1984;265:469.

4 Tower Hamlets Health Inquiry. Report. London: Tower Hamlets Health Inquiry, 1987.

5 Townsend P. Corrigan P, Kowarzik U. Poverty and labour in London. London: Low Pay Unit, 1987.

6 Jarman B. Identification of underprivileged areas. $\mathrm{Br} M e d$ f 1983;286:1705-9.

7 Usherwood TP, Kapasi MA, Barber JH. Wide variations in the night visiting rate. F $R$ Coll Gen Pract 1985;35:395

8 Riddell JA. Out-of-hours visits in a group practice. $B r M e d$ J 1980;280:1518-9.

9 Marsh GN, Horne RA, Channing DM. A study of telephone advice in managing out-of-hours calls. $f R$ Coll (jen Pract 1987;37:301-4.

10 Lockstone DR. Night calls in a group practice. $\mathcal{F} R$ Coll Gen Pract 1976;26: 68-71.

11 Ridsdill Smith RM. Out-of-hours calls. Update 1983;26:274-7.

12 National Audit Office. Management of family practitioner services. London: HMSO, 1988 .

13 Davison AG, Hildrey ACC, Floyer MA. Use and misuse of an accident and emergency department in the east end of London. F $R$ Soc Med 1983;76: $37-40$.

14 Department of Health and Social Security. Promoting better health: the government's programme for primary health care. London: HMSO, 1987.

15 Secretaries of State for Health, Wales, Northern Ireland, and Scotland. Working for patients. London: HMSO, 1989. (Cmnd 555.)

16 Department of Health and Welsh Office. General practice in the National Health Service. A new contract. London: Department of Health, 1989

17 Anonymous. Night calls, an emotional issue [Editorial]. I R Coll Gen Pract 1984;34:362-4

18 Pitt J. Hours of work and fatigue in doctors. $f$ R Coll Gen Pract 1988;38:2-3.

19 Harris A. Violence in general practice. Br Med $\mathcal{F}$ 1989;298:63-4.

20 Bosanquet N, Leese B. Family doctors and innovation in general practice. Br Med f 1988:296:1576-80.

21 Hobday P. Night workload in one health district. Br Med f 1984;289:663-4.

(Accepted 8 fune 1989)

\section{MATERIA PARAMEDICA}

\section{The prick test}

The prick test has been in steady use for many decades in the diagnosis of specific allergies in atopic subjects. A small drop of the suspected allergen in solution is placed on the skin. A pricker, preferably one specially designed for the purpose, enters the droplet and pierces the epidermis with a slight plucking motion. A positive response, indicating the presence of immunoglobulin $\mathrm{E}$ to the allergen, is manifested within minutes by the appearance of a weal surrounded by a hyperaemic zone, the flare.

Allergy to semen is fortunately exceedingly rare. It is, however, well documented. The response may be asthmatic or antaphylactic. A case of semen allergy was described some years ago at a meeting of the British Society for Allergy and Clinical Immunology. A married woman suffered severe and immediate symptoms after connubial intercourse. A member of the audience asked if the patient had tried intercourse with an extramarital partner, and if so with what result. Yes, was the reply, she had, and without ill effect. A wit in the audience exclaimed, "The prick test!" The use of "prick" for "penis" is now vulgar slang, but it was not always so. The Oxford English Dictionary quotes: (1592) "The pissing Boye lift up his pricke." John Aubrey, in the latter half of the seventeenth century, wrote of the lawyer John Selden (1584-1654) that his advancement was achieved more by sexual favours than by professional ability:

He came to the Inner-Temple . . . and was Sollicitor and Steward to the Earle of Kent, whose Countesse being an igeniose woman and loving men, would let him lye with her. . . . I remember my Sadler (who wrought many years to that Family) told me that Mr Selden had got more by his Prick then he had done by his practise. He was no eminent practiser at the Barre.

BERNARD J FREEDMAN 